\title{
Clique-Attacks Detection in Web Search Engine for Spamdexing using K-Clique Percolation Technique
}

\author{
S. K. Jayanthi and S. Sasikala, Member, IACSIT
}

\begin{abstract}
Search engines make the information retrieval task easier for the users. Highly ranking position in the search engine query results brings great benefits for websites. Some website owners interpret the link architecture to improve ranks. To handle the search engine spam problems, especially link farm spam, clique identification in the network structure would help a lot. This paper proposes a novel strategy to detect the spam based on K-Clique Percolation method. Data collected from website and classified with NaiveBayes Classification algorithm. The suspicious spam sites are analyzed for clique-attacks. Observations and findings were given regarding the spam. Performance of the system seems to be good in terms of accuracy.
\end{abstract}

Index Terms-Clique, link spam, search engine, ranking, search engine optimization.

\section{INTRODUCTION}

In the last few years, reaching relevant information through the use of search engines has become pervasive. Several sites on the web has growing portion of their traffic coming from search engines referrals. The increasing importance of search engines to commercial web sites has given rise to a phenomenon web spam, web pages that exist only to mislead search engines. The purpose of a ranking system is to assign a relative rank to a Web page according to the quality of the Web page. Although the quality of a Web page can mean many different things to different users, these qualities tend to make users prefer certain Web pages over others and express their endorsements in the form of hyperlinks. Therefore, it is reasonable to expect that when the vast link structure of the Web is analyzed properly, spam could be detected.

\section{Clique AND WEB SpamdeXING}

A clique is a subgraph in which all nodes are mutually connected to each other by edges. Cliques of size 3, 4 and 5 are shown in Fig 1.
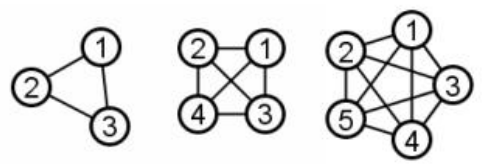

Fig. 1. Clique of size 3, 4 and 5

Manuscript received July 19, 2012; revised August 20, 2012

S. K. Jayanthi was with Department of Computer Science, Vellalar College for women, Erode-12, India. (e-mail: jayanthiskp@gmail.com).

S. Sasikala was with the Department of Computer Science, KSR College of Arts and Science,Tiruchengode-637211, India (e-mail:sasi sss 123 (arediff.com)
Clique cluster groups the set of nodes that are completely connected to each other. Specifically if connections are added between objects in the order of their distance from one another a cluster if formed when the objects forms a clique. If a web site is considered as a clique, then incoming and outgoing links analysis reveals the cliques existence in web. It means strong interconnection between few websites with mutual link interchange. It improves all websites rank, which participates in the clique cluster. In Fig. 2 one particular case of link spam, link farm spam is portrayed. That figure points one particular node (website) is pointed by so many nodes (websites), this structure gives higher rank for that website as per the PageRank algorithm. Because that algorithm is focussing on the link details.

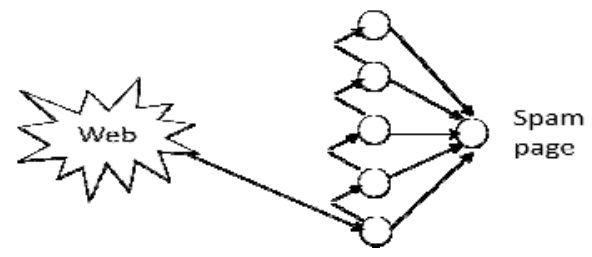

Fig. 2. Link Farm Spam

III. RELATED LITERATURE

\begin{tabular}{|c|c|c|c|c|}
\hline No & Author name & Title & Focused on & Proposed \\
\hline 1 & $\begin{array}{l}\text { Baoning Wu } \\
\text { and Brian D. } \\
\text { Davison }\end{array}$ & $\begin{array}{l}\text { Identifying } \\
\text { Link Farm } \\
\text { Spam Pages }\end{array}$ & $\begin{array}{l}\text { Link Farms, } \\
\text { TKC Effect }\end{array}$ & $\begin{array}{l}\text { Two algorithms. } \\
\text { 1. Seed set selection : } \\
\text { Common link sets } \\
\text { within the incoming and } \\
\text { outgoing links of Web } \\
\text { pages are considered for } \\
\text { selecting the seed set } \\
\text { 2. ParentPenalty: } \\
\text { Expanding the seed set } \\
\text { to include more pages } \\
\text { within certain link } \\
\text { farms. This spamming } \\
\text { page set can be used } \\
\text { together with ranking } \\
\text { algorithms such as HITS } \\
\text { or PageRank to generate } \\
\text { new ranking lists. }\end{array}$ \\
\hline 2 & $\begin{array}{l}\text { Baoning Wu, } \\
\text { Brian D. } \\
\text { Davison }\end{array}$ & $\begin{array}{l}\text { Undue } \\
\text { Inuence: } \\
\text { Eliminating the } \\
\text { Impact of } \\
\text { Link } \\
\text { Plagiarism on } \\
\text { Web Search } \\
\text { Rankings_ }\end{array}$ & $\begin{array}{l}\text { link farm } \\
\text { spam, } \\
\text { replicated } \\
\text { pages and } \\
\text { complete } \\
\text { hyper- } \\
\text { links }\end{array}$ & $\begin{array}{l}\text { 1. Algorithm for Finding } \\
\text { bipartite components. } \\
\text { Based on this concept, they } \\
\text { extract one or more complete } \\
\text { links from each HTML } \\
\text { document and build a } \\
\text { document-hyperlink matrix } \\
\text { for these pages. The bipartite } \\
\text { subgraph within this matrix is } \\
\text { a good indication of duplicate } \\
\text { pages or link farms. Final } \\
\text { adjustment in hyperlink } \\
\text { matrix } \\
\text { They penalize such links. }\end{array}$ \\
\hline
\end{tabular}




\begin{tabular}{|c|c|c|c|c|}
\hline & & & & $\begin{array}{l}\text { After finding these duplicate } \\
\text { complete links they punish } \\
\text { them by down-weighting } \\
\text { them in the adjacency matrix } \\
\text { and then calculate HITS } \\
\text { results. Their policy is only } \\
\text { to punish links, but not to } \\
\text { ban pages containing these } \\
\text { links. }\end{array}$ \\
\hline 3 & $\begin{array}{l}\text { Zoltan } \\
\text { Gyongyi, } \\
\text { Hector Garcia } \\
\text { Molina }\end{array}$ & $\begin{array}{l}\text { Web Spam } \\
\text { Taxonomy }\end{array}$ & $\begin{array}{l}\text { Boosting } \\
\text { Techniques, } \\
\text { Hiding } \\
\text { Techniques, } \\
\text { Cloaking and } \\
\text { redirection }\end{array}$ & $\begin{array}{l}\text { They presented a variety of } \\
\text { commonly used web } \\
\text { spamming techniques, and } \\
\text { organized } \\
\text { them into a taxonomy. }\end{array}$ \\
\hline 4 & $\begin{array}{l}\text { Zoltan } \\
\text { Gyongyi, } \\
\text { Hector Garcia } \\
\text { Molina, Jan } \\
\text { Pedersen }\end{array}$ & $\begin{array}{l}\text { Combating } \\
\text { Web Spam } \\
\text { with TrustRank }\end{array}$ & $\begin{array}{l}\text { Spam web } \\
\text { pages }\end{array}$ & $\begin{array}{l}\text { TrustRank algorithm for } \\
\text { determining the likelihood } \\
\text { that pages are reputable. } \\
\text { 1. A trust score is calculated } \\
\text { 2. Trust propagation } \\
\text { 3. Trust Attenuation }\end{array}$ \\
\hline 5 & $\begin{array}{l}\text { Jon M. } \\
\text { Kleinberg }\end{array}$ & $\begin{array}{l}\text { Authoritative } \\
\text { Sources in a } \\
\text { Hyperlinked } \\
\text { Environment }\end{array}$ & $\begin{array}{l}\text { Search } \\
\text { engine }\end{array}$ & $\begin{array}{l}\text { HITS Ranking algorithm } \\
\text { Hubs and Authorities }\end{array}$ \\
\hline 6 & $\begin{array}{l}\text { Yong Wang, } \\
\text { Zhiguang Qin, } \\
\text { Bin Tong, and } \\
\text { Jing Jin }\end{array}$ & $\begin{array}{l}\text { Link Farm } \\
\text { Spam } \\
\text { Detection } \\
\text { Based on Its } \\
\text { Properties } \\
\end{array}$ & $\begin{array}{l}\text { Link Farm } \\
\text { Spam }\end{array}$ & $\begin{array}{l}\text { Analyzed the degree } \\
\text { distribution and average path } \\
\text { length properties of Web } \\
\text { network for link farm spam }\end{array}$ \\
\hline 7. & $\begin{array}{l}\text { Qi Chen, } \\
\text { Song-Nian Yu, } \\
\text { Sisi Cheng }\end{array}$ & $\begin{array}{l}\text { Link Variable } \\
\text { TrustRank for } \\
\text { Fighting Web } \\
\text { Spam }\end{array}$ & Spam sites & $\begin{array}{l}\text { Variance of link structure is } \\
\text { taken into consideration, } \\
\text { combining with which the } \\
\text { ranking scores of websites } \\
\text { are judged. }\end{array}$ \\
\hline 8. & $\begin{array}{l}\text { Andras A. } \\
\text { Benczur, Dav } \\
\text { Siklosi, Jacint } \\
\text { Szabo, Iidstvan } \\
\text { Bíro, Zsolt } \\
\text { Fekete, } \\
\text { Miklos } \\
\text { Kurucz, Attila } \\
\text { Pereszlenyi, } \\
\text { Simon Racz, } \\
\text { Adrienn Szabo }\end{array}$ & $\begin{array}{l}\text { Web Spam: a } \\
\text { Survey with } \\
\text { Vision for the } \\
\text { Archivist }\end{array}$ & $\begin{array}{l}\text { Web } \\
\text { archives }\end{array}$ & $\begin{array}{l}\text { Surveyed existing } \\
\text { methodology and envision a } \\
\text { solution for Web archives to } \\
\text { share knowledge and unite } \\
\text { efforts in Web spam hunting. } \\
\text { They focus on LiWA FP7 } \\
\text { project for preventing, } \\
\text { detecting and eliminating } \\
\text { web spam }\end{array}$ \\
\hline 9. & $\begin{array}{l}\text { Jacob } \\
\text { Abernethy, } \\
\text { Olivier } \\
\text { Chapelle, } \\
\text { Carlos Castillo }\end{array}$ & $\begin{array}{l}\text { Graph } \\
\text { regularization } \\
\text { methods } \\
\text { forWeb spam } \\
\text { detection }\end{array}$ & Web graph & $\begin{array}{l}\text { WITCH Algorithm, that } \\
\text { learns to detect spam hosts or } \\
\text { pages on the Web. Unlike } \\
\text { most other approaches, it } \\
\text { simultaneously exploits the } \\
\text { structure of the Web graph as } \\
\text { well as page contents and } \\
\text { features. }\end{array}$ \\
\hline 10. & $\begin{array}{l}\text { Nikita Spirin, } \\
\text { Jiawei Han }\end{array}$ & $\begin{array}{l}\text { Survey on Web } \\
\text { Spam } \\
\text { Detection: } \\
\text { Principles and } \\
\text { Algorithms }\end{array}$ & $\begin{array}{l}\text { Principles } \\
\text { and } \\
\text { Algorithms }\end{array}$ & $\begin{array}{l}\text { They present a systematic } \\
\text { review of web spam } \\
\text { detection techniques with the } \\
\text { focus on algorithms and } \\
\text { underlying principles. }\end{array}$ \\
\hline
\end{tabular}

IV. Web SEARCh ENGINE SPAMdEXING EXTRACTION USING K-CPM METHOD

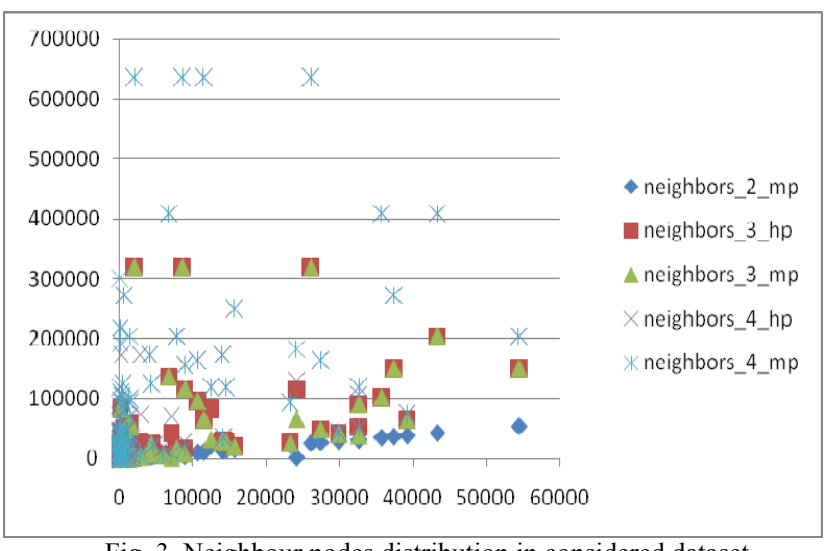

Fig. 3. Neighbour nodes distribution in considered dataset
The details of the neighbour nodes reveal the link farm in many aspects. The distributions of the neighbour nodes in considered dataset are shown in Fig. 3. Maximal cliques are unique and not contained in others. By extracting maximum cliques, the hub of a link-farm can be captured. The steps are given briefly below. And the backtracking has been implied after that to further refine the results.

Step 1: Find the maximal cliques present in website

Step 2: Cluster sites according to the common nodes

Step 3: Sort and Load the edges of the undirected graph

Step 4: If there is a bipartite scenario count the commonly linked nodes. This is complete link exchanges. Two websites mutually share the links and both get higher rank. Consider two websites A and B. Site A contributes all outgoing links to $\mathrm{B}$ and $\mathrm{B}$ in turn contributes all outgoing links to $\mathrm{A}$.

Step 5: If the number of commonly linked nodes is above a certain threshold THR, then nodes are clustered in the same set.

\section{Finding k-cliques using KCPM}

CliqueBT (Vector A, j)

\{

// If $\mathrm{j}$ is equal to size of clique, $\mathrm{k}$, then $\mathrm{A}$ is $\mathrm{k}$-clique in the webgraph

if $(\mathrm{j}==$ sizeClique $)$ then

do

\{

numClique++

return

\}

else

\{

$\mathrm{j}=\mathrm{j}+1$ and if $(\mathrm{j}<=$ sizeClique $)$ then do

\{

// Let $\mathrm{Sj}$ is the set of all candidate vectors

for $\mathrm{j}$-clique

$\mathrm{Sj}=$ getCandidates $(\mathrm{A})$

\} if $(\mathrm{Sj}$ is NOT empty)

\{

// For each candidate vector in $\mathrm{Sj}$, recursively do backtracking for k-clique

for (each candidate vector aj in $\mathrm{Sj}$ )

do

CliqueBT (aj , j)

\}) \}

\section{DATASET}

The dataset used in this experiment is collected with information retrieval system which retrieves the inlinks, outlinks and various features listed in Section VI. As a result the numerical values were retrieved from the websites. Samples of five websites were given in Table II. The dataset will be in Excel format which can then be transferred to ARFF format.

After the data collection and preprocessing is over, the classification task is carried out to narrow down the suspicious websites. NaïveBayes Classifier is used here. The suspicious websites are again subject to analysis with utility websphinx and further refined and cliques detected from the dataset. 


\section{Clique EXTRACTION AND OBSERVATIONS}

Analyzing the link properties of website such as indegree (number of inliks), outdegree(number of outlinks), in_out average( for home page and other pages), Pagerank reveals the presence of the spam. The inlinks and outlinks has the intersections (same node acting as inlink and outlink) which is an important aspect to determine the link farm. The Pagerank is considered because it is computed based on the link properties of the website. Totally twelve features are considered and finally the presence of cliques is determined based on the link spamcity score. They are listed below.

1. F1-avgin_of_out_hp - Average in-degree of out-neighbors of home page (hp)

2. F2-avgin_of_out_mp - Average in-degree of out-neighbors of page with maximum PageRank (hp)

3. F3-avgout_of_in_hp - Average out-degree of in-neighbors of $h p$

4. F4-avgout_of_in_mp - Average out-degree of in-neighbors of $m p$

5. F5-indegree_hp-Indegree of $h p$

6. F6-indegree_mp - Indegree of $m p$

7. F7-outdegree_hp-Out-degree of $h p$

8. F8-outdegree_mp-Out-degree of $m p$

9. F9-pagerank_hp - PageRank of hp (calculated in the doc graph with no self-loops, using a damping factor of 0.85, with 50 iterations)

10. F10-pagerank_mp - PageRank of mp

11. F11-trustrank_hp - TrustRank of $h p$

12. F12-trustrank_mp - TrustRank of $m p$

Cliques are extracted from the inspected suspicious sites and it is also noticed. Initially the mentioned features are retrieved from the website through web retrieval system. And all the values are processed and consolidated.

With the consolidated data, spamcity score is calculated using Eqn. 1.

$$
\text { Link_Spam_Score }(W P)=\frac{P R(W P)}{\frac{1}{n} \sum_{\text {wp'? }} \operatorname{PR}\left(W^{\prime}\right)}
$$

A sample calculation of link spam score based on the feature values is given in Table I. Based on the spamcity score the website will be further examined for the presence of link farm in the format of cliques. The link spamicity of a web page is between 0 and 1 . The higher the link spamicity, the more the page farm is utilized to boost the PageRank of the target page. If the spamcity score is higher than the threshold $\alpha$ spam is confirmed. Here $\alpha=0.5$. The navigational pattern of the website remains cyclic and the samples are listed in Table II. Here the numerical values for features are given.

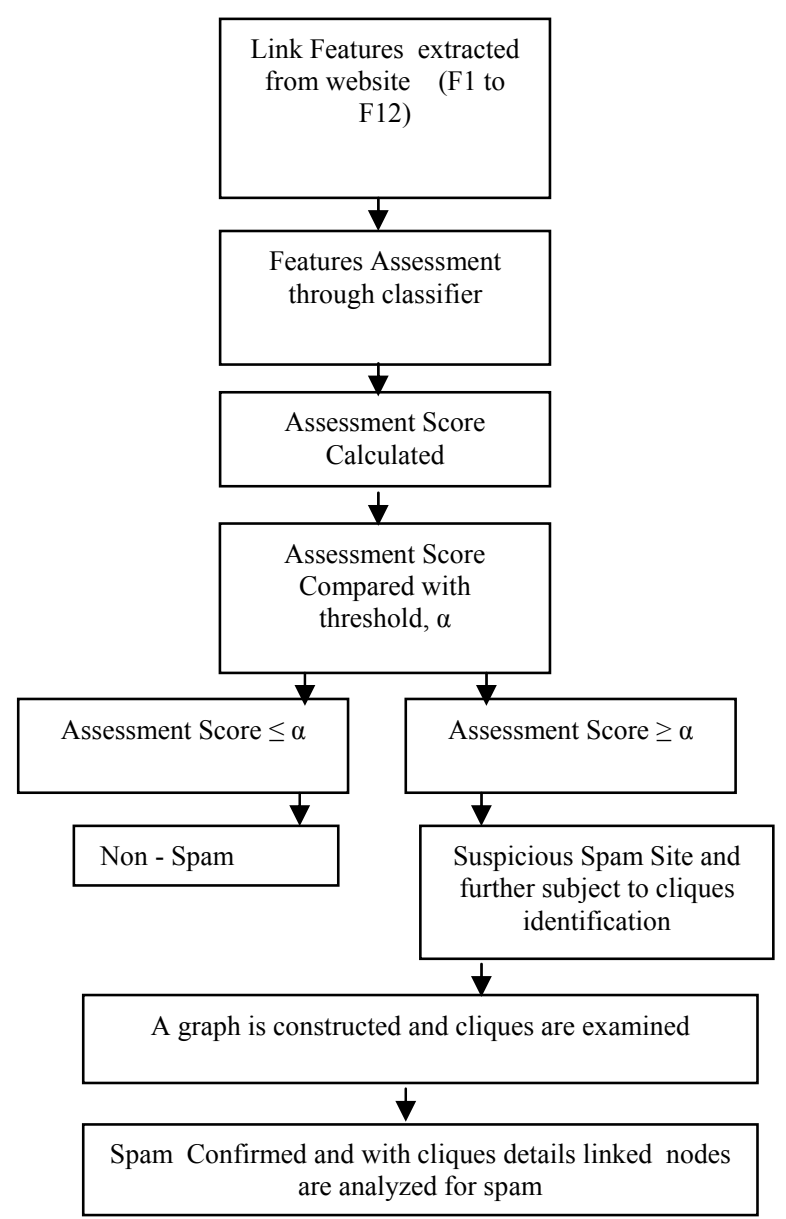

Fig.4. Process of Clique Attacks Detection

Based on the link spam scores the results are further analyzed for the cliques and if it is present then the neighbor nodes are also analyzed for two levels.

Sample values observed while feature extraction are listed in Table II and Fig. 5 represents the in-degree distribution of the considered dataset, Fig. 6 represents the outdegree distribution and Fig. 7 indicates the average of the in and out links in the dataset.

Fig. 4 represents the cliques attacks detection process. Initially the considered dataset is subject to spamcity score calculation and if the score exceeds the threshold then that particular website is analyzed for cliques.

\begin{tabular}{|c|c|c|c|c|c|c|c|c|c|c|c|c|c|c|}
\hline Sno & Host name & $\mathrm{F} 1$ & F2 & F3 & F4 & F5 & F6 & F7 & F8 & F9 & F10 & F11 & F12 & $\begin{array}{l}\text { Link } \\
\text { spamcity } \\
\text { assessment } \\
\text { score }\end{array}$ \\
\hline 1 & $\begin{array}{l}\text { 109belfast.boys-brigade.o } \\
\text { rg.uk }\end{array}$ & $\begin{array}{l}9.908 \\
127 \\
\end{array}$ & $\begin{array}{l}9.908 \\
127 \\
\end{array}$ & $\begin{array}{l}5.476 \\
464 \\
\end{array}$ & $\begin{array}{l}5.476 \\
464 \\
\end{array}$ & $\begin{array}{l}1.386 \\
294\end{array}$ & $\begin{array}{l}1.386 \\
294\end{array}$ & 0 & 0 & $\begin{array}{l}19.93 \\
63 \\
\end{array}$ & $\begin{array}{l}19.93 \\
63 \\
\end{array}$ & $\begin{array}{l}21.24 \\
43 \\
\end{array}$ & $\begin{array}{l}21.24 \\
43 \\
\end{array}$ & 0.000 \\
\hline 2 & $\begin{array}{l}\text { 2accrington.boys-brigade. } \\
\text { org.uk }\end{array}$ & $\begin{array}{l}3.178 \\
054 \\
\end{array}$ & $\begin{array}{l}3.178 \\
054 \\
\end{array}$ & $\begin{array}{l}1.609 \\
438 \\
\end{array}$ & $\begin{array}{l}1.609 \\
438 \\
\end{array}$ & $\begin{array}{l}0.788 \\
457 \\
\end{array}$ & $\begin{array}{l}0.788 \\
457 \\
\end{array}$ & $\begin{array}{l}3.781 \\
345 \\
\end{array}$ & $\begin{array}{l}3.781 \\
345 \\
\end{array}$ & $\begin{array}{l}17.07 \\
8\end{array}$ & $\begin{array}{l}17.07 \\
8\end{array}$ & $\begin{array}{l}18.46 \\
46 \\
\end{array}$ & $\begin{array}{l}18.46 \\
46 \\
\end{array}$ & 1.000 \\
\hline 3 & asami07.cs.rhul.ac.uk & $\begin{array}{l}1.945 \\
91\end{array}$ & $\begin{array}{l}1.945 \\
91\end{array}$ & $\begin{array}{l}0.693 \\
147 \\
\end{array}$ & $\begin{array}{l}0.693 \\
147 \\
\end{array}$ & $\begin{array}{l}2.674 \\
149 \\
\end{array}$ & $\begin{array}{l}2.674 \\
149 \\
\end{array}$ & $\begin{array}{l}2.824 \\
775\end{array}$ & $\begin{array}{l}2.824 \\
775\end{array}$ & $\begin{array}{l}18.31 \\
58\end{array}$ & $\begin{array}{l}18.31 \\
58\end{array}$ & $\begin{array}{l}19.31 \\
23\end{array}$ & $\begin{array}{l}19.31 \\
23\end{array}$ & 0.500 \\
\hline 4 & atangledweb.co.uk & $\begin{array}{l}4.304 \\
065 \\
\end{array}$ & $\begin{array}{l}4.304 \\
065 \\
\end{array}$ & $\begin{array}{l}2.708 \\
05 \\
\end{array}$ & $\begin{array}{l}2.708 \\
05 \\
\end{array}$ & $\begin{array}{l}4.815 \\
228 \\
\end{array}$ & $\begin{array}{l}4.815 \\
228 \\
\end{array}$ & $\begin{array}{l}2.741 \\
711 \\
\end{array}$ & $\begin{array}{l}2.741 \\
711 \\
\end{array}$ & $\begin{array}{l}18.26 \\
67 \\
\end{array}$ & $\begin{array}{l}18.26 \\
67 \\
\end{array}$ & $\begin{array}{l}19.66 \\
33 \\
\end{array}$ & $\begin{array}{l}19.66 \\
33 \\
\end{array}$ & 0.500 \\
\hline 5 & beehive.thisisexeter.co.uk & $\begin{array}{l}7.986 \\
505 \\
\end{array}$ & $\begin{array}{l}7.986 \\
505 \\
\end{array}$ & $\begin{array}{l}3.496 \\
508 \\
\end{array}$ & $\begin{array}{l}3.496 \\
508 \\
\end{array}$ & $\begin{array}{l}10.40 \\
57 \\
\end{array}$ & $\begin{array}{l}10.40 \\
57 \\
\end{array}$ & $\begin{array}{l}3.273 \\
449 \\
\end{array}$ & $\begin{array}{l}3.273 \\
449 \\
\end{array}$ & $\begin{array}{l}14.08 \\
33 \\
\end{array}$ & $\begin{array}{l}14.08 \\
33 \\
\end{array}$ & $\begin{array}{l}14.79 \\
52 \\
\end{array}$ & $\begin{array}{l}14.79 \\
52 \\
\end{array}$ & 0.750 \\
\hline
\end{tabular}




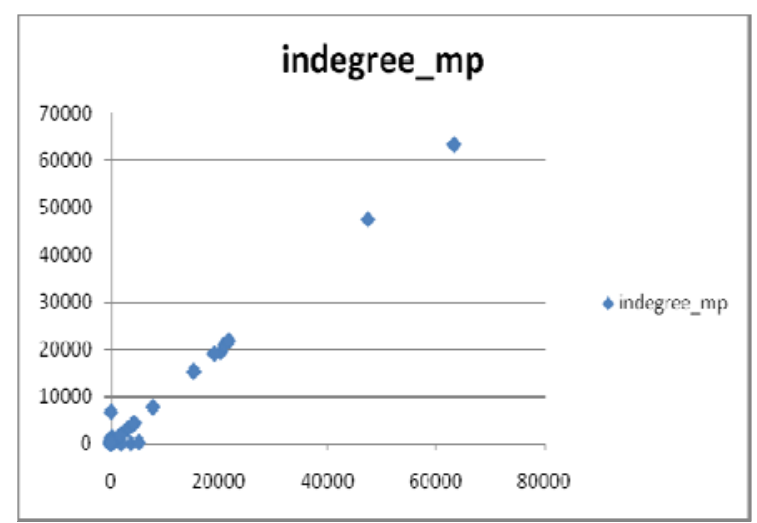

Fig. 5. Distribution of in-degree

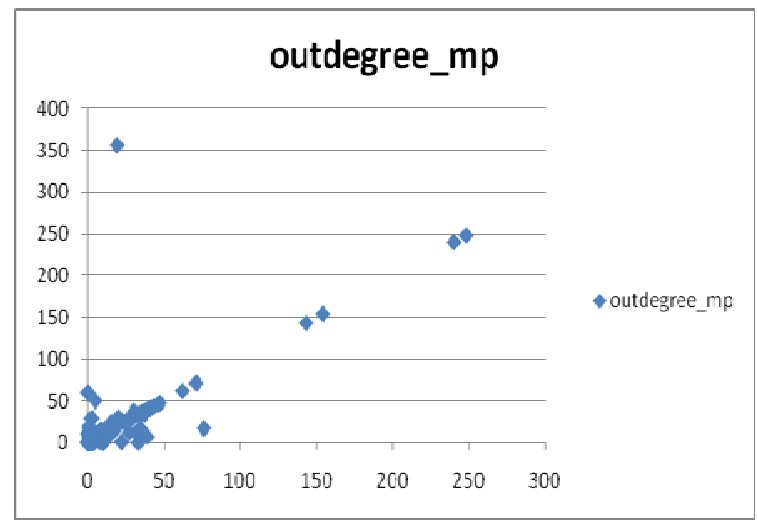

Fig. 6. Distribution of out-degree

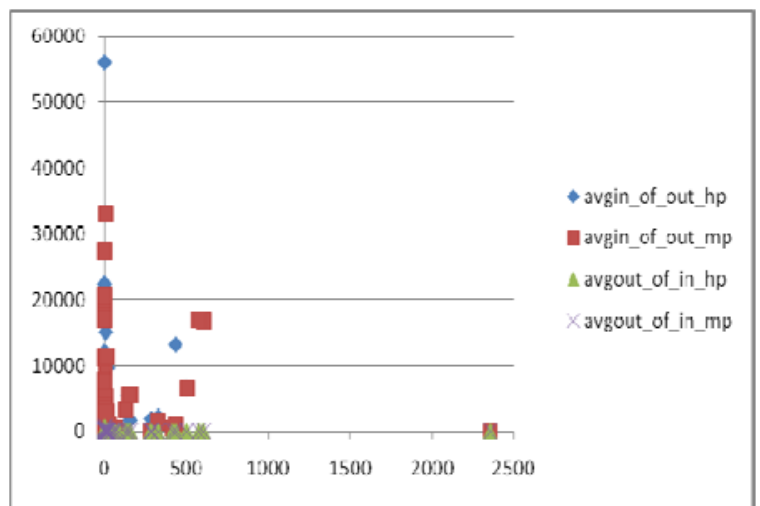

Fig. 7. Distribution of out-degree and in-degree average for home page and other pages

\section{EXPERIMENTAL RESULTS}

The results can be outlined as follows. (Due to space constraint only few results have been listed.). Consider classifier $\mathrm{C}$ and a test set of documents D. Classifier C computes a label for each document $p \in D$. Let $C(p)=1$ if $p$ is classified spam and $C(p)=0$ otherwise. Let $S \in D$ and $N \in$ $\mathrm{D}$ denote the set of spam and normal pages $(\mathrm{S} \in \mathrm{N}=\mathrm{D})$. The algorithm categorizes each document in $\mathrm{D}$ as spam or a normal page. Let denote SC and NC the set of pages that are detected spam and normal by the algorithm. In summary:

$$
\begin{gathered}
\mathrm{S}=\{\mathrm{p} \in \mathrm{D} \mid \mathrm{p} \text { is spam }\} \\
\mathrm{N}=\{\mathrm{p} \in \mathrm{D} \mid \mathrm{p} \text { is not spam }\} \\
\mathrm{SC}=\{\mathrm{p} \in \mathrm{D} \mid \mathrm{C}(\mathrm{p})=1\} \\
\mathrm{NC}=\{\mathrm{p} \in \mathrm{D} \mid \mathrm{C}(\mathrm{p})=0\}
\end{gathered}
$$

The following metrics are used for evaluation:

- true positives are the spam documents that are correctly detected as spam, $\mathrm{TPC}=\mathrm{S} \cap \mathrm{SC}$.
- true negatives are the normal documents that are correctly detected as normal,

$\mathrm{TNC}=\mathrm{N} \cap \mathrm{NC}$.

- false positives are the normal documents that are incorrectly detected as spam, $\quad \mathrm{FPC}=\mathrm{N} \cap \mathrm{SC}$.

- false negatives are the spam documents that are incorrectly detected as normal, $\quad \mathrm{FNC}=\mathrm{S} \cap \mathrm{NC}$.

The two-by-two matrix of these values forms the confusion matrix:

\begin{tabular}{l|ll}
\multicolumn{2}{c}{ TABLE III: Evaluation Metrics } \\
\hline & Actual Positive & Actual Negative \\
\hline Predicted Positive & True Positive & False Positive \\
Predicted Negative & False Negative & True Negative \\
\hline
\end{tabular}

$$
\begin{aligned}
& \text { Precision }=\frac{t p}{t p+f p} \\
& \text { Recall }=\frac{t p}{t p+f n} \\
& \text { True negative rate }=\frac{t n}{t n+f p} \\
& \text { Aceuracy }=\begin{array}{c}
t p-t p \\
t p+t n+f p+f n
\end{array}
\end{aligned}
$$

The two-by-two matrix of these values forms the confusion matrix for the NaïveBayes classifier shown in Table IV.

TABLE IV: CONFUSION MATRIX GENERATED BY NAÏVEBAYES CLASSIFIER

\begin{tabular}{|ccc|}
\hline \multicolumn{3}{|c|}{$===$ Confusion Matrix $===$} \\
\hline $\mathrm{a}$ & $\mathrm{b}$ & $<-$ - classified as \\
\hline 212 & 10 & $\mathrm{a}=$ spam \\
\hline 67 & 3709 & $\mathrm{~b}=$ nonspam \\
\hline
\end{tabular}

The results generated by the NaiveBayes classifier is given below:

$===$ Stratified cross-validation $===$ $===$ Summary $===$

Correctly Classified Instances $\quad 3921$

Incorrectly Classified Instances $\quad 77$

$98.074 \%$

Kappa statistic

$77 \quad 1.926 \%$

Mean absolute error $\quad 0.0216$

Root mean squared error $\quad 0.1334$

Relative absolute error $\quad 20.5865 \%$

Root relative squared error $\quad 58.2658 \%$

Coverage of cases (0.95 level) $\quad 98.6493 \%$

Mean rel. region size ( 0.95 level) $\quad 51.063 \%$

Total Number of Instances 3998

TABLE V: ACCURACY TABLE

$===$ Detailed Accuracy By Class $===$

\begin{tabular}{|cclllllr|}
\hline TP Rate & FP Rate & Precision & Recall & F-Measure & ROC Area Class \\
\hline 0.955 & 0.018 & 0.76 & 0.955 & 0.846 & 0.981 & spam \\
\hline 0.982 & 0.045 & 0.997 & 0.982 & 0.99 & 0.981 & normal \\
\hline Weighted Avg. & & & & & \\
\hline 0.981 & 0.044 & 0.984 & 0.981 & 0.982 & 0.981 & \\
\hline
\end{tabular}

As mentioned in the Table IV, the 212 (true positives) websites are taken for the cliques attacks detection and among them many communities strongly interlinking are detected. 
Sometimes search engine optimization is applied to genuine websites which may seems like the spam. Those sites are again classified as non-spam in Table VI.

TABLE VI: SPAM CLASSIFICATION IN ANALYZED WEBSITES

\begin{tabular}{l|ll}
\hline Classification Type & Sites & Ratio \\
\hline Non-Spam & 48 & 24.05 \\
Sales & 69 & 31.96 \\
Pharmaceuticals & 3 & 1.71 \\
Sexually Explicit & 92 & 42.26 \\
\hline Total & 212 & $100 \%$ \\
\hline
\end{tabular}

The assessment score acquired is plotted as a graph in Fig 8 . When the assessment score is $>0.5(\alpha)$ then they are plotted as spam and if it is $<0.5(\alpha)$ it is genuine. For the considered dataset the graph is plotted in Fig 8 .

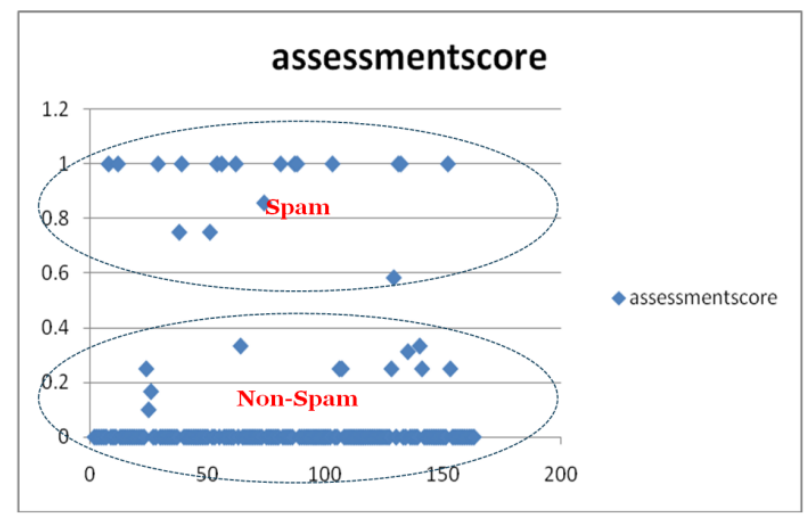

Fig. 8. Assessment score comparison in given dataset

An ROC space is defined by FPR and TPR as $\mathrm{x}$ and $\mathrm{y}$ axes respectively, which depicts relative trade-offs between true positive (benefits) and false positive (costs). Since TPR is equivalent with sensitivity and FPR is equal to 1 - specificity, the ROC graph is sometimes called the sensitivity vs (1specificity) plot. Each prediction result or instance of a confusion matrix represents one point in the ROC space. The Roc curve generated for the naivebayes classifier is given. Here in this experiment AUC for ROC is 0.9809 . This is a better result which shows more accurate classification. Fig. 9 shows the ROC curve generated by the NaiveBayes classifier and Fig. 10 shows the cost-benefit analysis for the same.

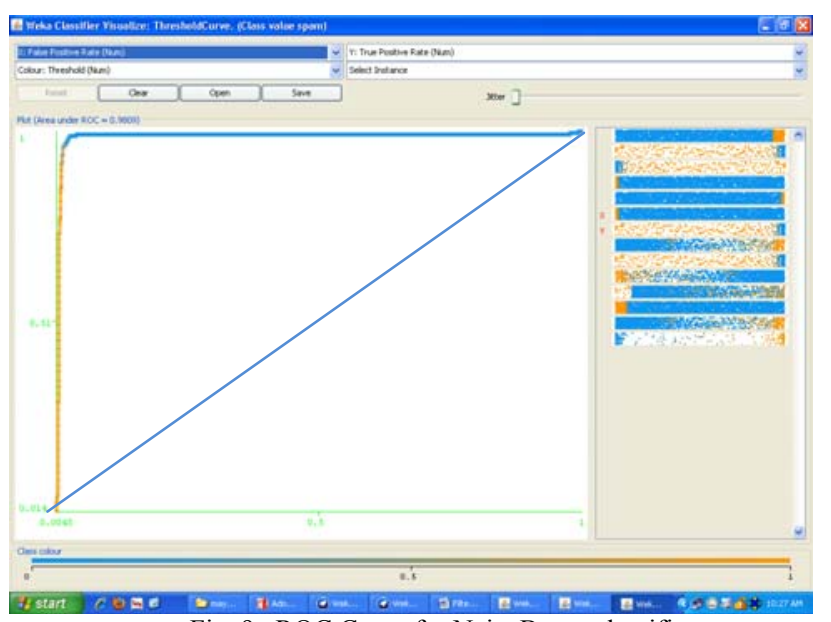

Fig. 9. ROC Curve for NaiveBayes classifier

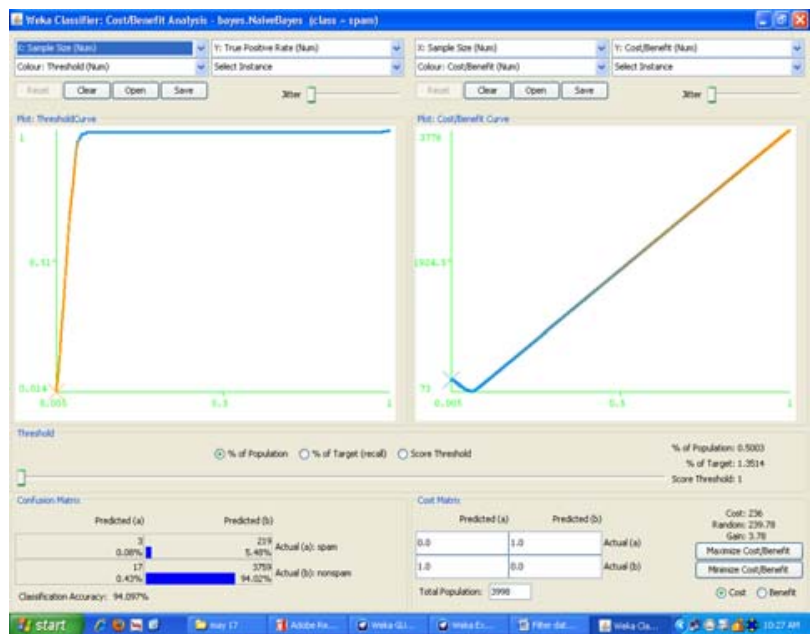

Fig. 10. Cost-benefit analysis for NaiveBayes classifier

Fig. 11 represents a spam website http://www.mobicreed.com where the spam is indicated as red color circle. It actually shows 48,213 links but majority of the links are from the same website. The major link contributor for the website is the same website itself. A cyclic structure is created here.
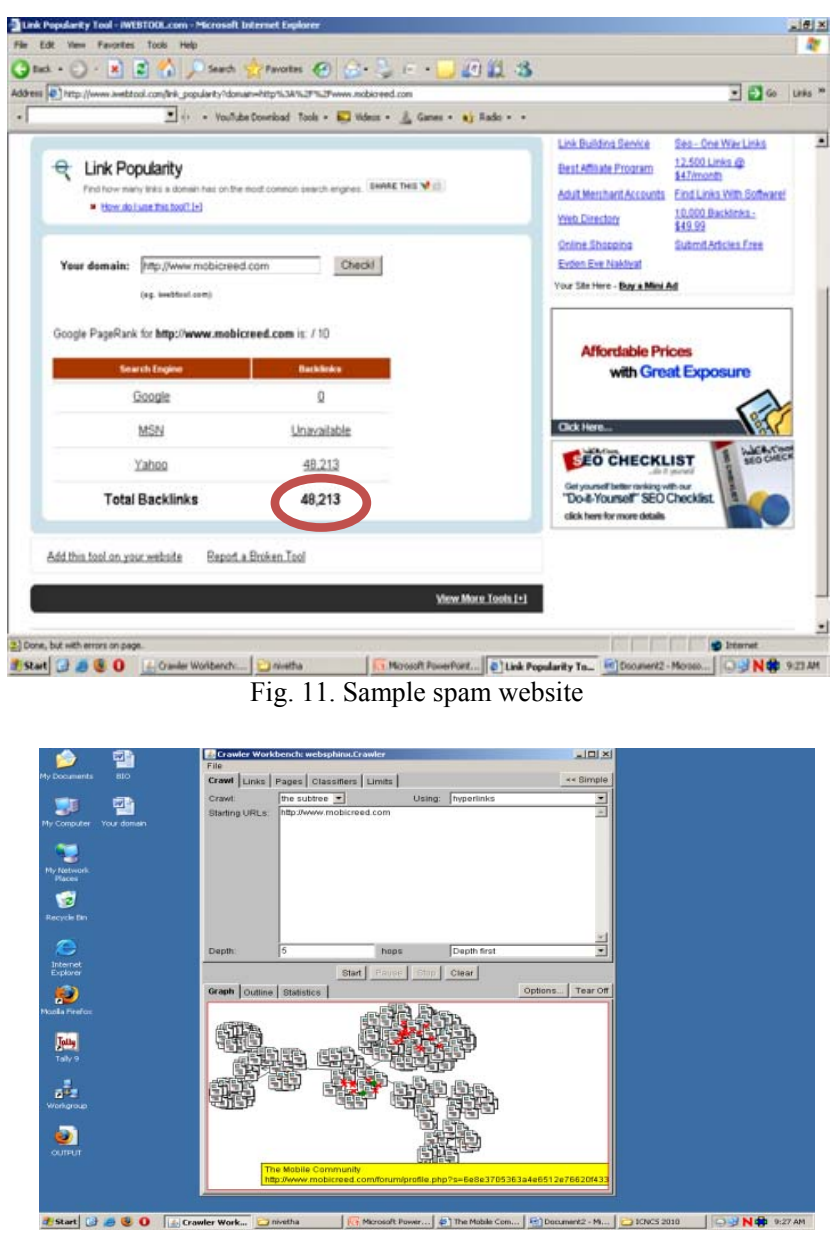

Fig. 12. Spam in hyperlinks- spam is represented as red highlighted

In Fig.12, the websphinx utility is used and it derives the entire graph for the spam website http://www.mobicreed.com. Once a website is classified as spam it will be further subject to the clique attacks. The detection of clique attacks is done through the analyzing the major link contributor website. Here for 212 nodes the analysis is done. This illustrated 
example is for clique attack analysis for the mentioned spam site. Fig 13 represents the category classification of the 212 nodes.

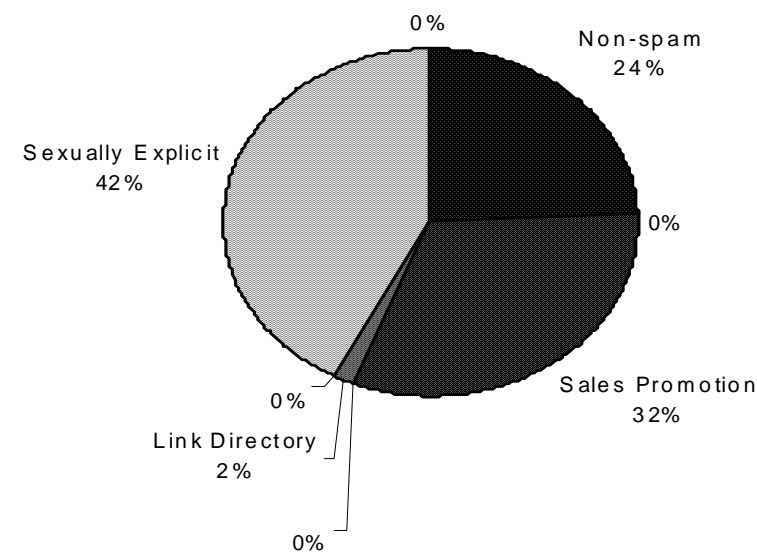

Fig. 13. Ratio of spam classification and maximum cliques in analyzed websites

\section{CONCLUSION}

The objective of this paper was to classify webspam in given dataset and from the result the cliques are detected. This paper proposes a novel strategy that can be used to filter the spam which possesses the clique attacks. It addresses the link spam type of clique in web search engine. For that the web graph has been created to study the topology of the web site to determine the occurrence of the spam. The inlink, outlink are retrieved from the website with the help of a utility.The suggested approach helps to improve the efficiency in link spam detection by analyzing additional link farms based on constraints as motioned in the algorithm. Based on the recall and precision metrics, conclusion can be made that the proposed system efficiently detects the spam pages. One of the possible improvements is by integrating the weight of web page content relevancy into clique tracking and formulating a collaborative constraint based filter.

\section{REFERENCES}

[1] B. Wu and Brian D. Davison, "Identifying Link Farm Spam Pages," in Proc. International World Wide Web Conference (IW3C2) WWW, 2005, pp. $820-829$.

[2] B. Wu and Brian D. Davison, "Undue Influence: Eliminating the Impact of Link Plagiarism on Web Search Rankings," Technical Report LU-CSE-06-007, Department of Computer Science and Engineering, pp. 1-25, 2006.

[3] Z. Gyongyi and Hector Garcia Molina, "Web Spam Taxonomy," Technical report, Stanford Digital Library Technologies Project, pp.1-11, 2004.
[4] Z. Gyongyi, Hector Garcia Molina, and Jan Pedersen, "Combating Web Spam with TrustRank," in Proc. of the 30th VLDB Conference, 2004, pp.576-587.

[5] Jon M. Kleinberg, "Authoritative Sources in a Hyperlinked Environment," in Proc. ACM-SIAM Symposium on Discrete Algorithms, 1998, pp.1-34.

[6] Y. Wang, Z. Qin, B. Tong, and J. Jin, "Link Farm Spam Detection Based on Its Properties," in Proc. International Conference on Computational Intelligence and Security, 2008, pp. 477-480.

[7] Qi Chen, Song-Nian Yu, and S.Cheng, "Link Variable TrustRank for Fighting Web Spam," in Proc. International Conference on Computer Science and Software Engineering, 2008, pp. 1004-1007.

[8] A. Benczur, D. Siklosi, J. Szabo, I. Bíro, Z. Fekete, M. Kurucz, A.Pereszlenyi, S. Racz and A. Szabo , "Web Spam: a Survey with Vision for the Archivist," in Proc. IWAW'08 International Web Archiving Workshop, 2008.

[9] J.Abernethy, O. Chapelle, C. Castillo, "Graph regularization methods for Web spam detection," Springer Mach Learn, pp. 207-225, 2010.

[10] N. Spirin, Jiawei Han, "Survey on Web Spam Detection: Principles and Algorithms," Newsletter ACM SIGKDD Explorations Newsletter archive, vol. 13, Issue 2, 2011.

[11] S. K.Jayanthi and S. Sasikala, "Perceiving LinkSpam based on DBSpamClust," in Proc. IEEE International Conference on Network and Computer Science, IEEE Press, New York, 2011, pp. 31-35.

[12] S. K. Jayanthi and S. Sasikala, "Link Spam Detection based on Fuzzy C-Means Clustering," I. J. Next-Generation Networks, 198, pp. 1-10 2010.

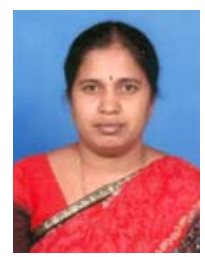

Dr. S. K. Jayanthi received the M.Sc., M.Phil, PGDCA, $\mathrm{Ph} . \mathrm{D}$ in Computer Science from Bharathiar University in $1987,1988,1996$ and 2007 respectively. She is currently working as an Asso.Professor, Head of the Department of Computer Science in Vellalar College for Women. She secured District First Rank in SSLC under Backward Community. Her research interest includes Image Processing, Pattern Recognition and Fuzzy Systems. She has guided 18 M.Phil Scholars and currently 4 M.Phil Scholars and $4 \mathrm{Ph}$.D Scholars are pursuing their degree under her supervision. She is a member of ISTE, IEEE and Life Member of Indian Science Congress. She has published 9 papers in International Journals and one paper in National Journal and published an article in Reputed Book. She has presented 21 papers in International level Conferences/Seminars, 20 papers in National level Conferences/Seminars and participated in around 35 Workshops/Seminars/Conferences/FDP.

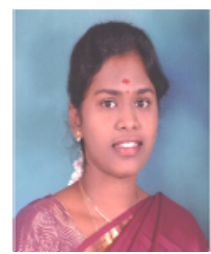

S. Sasikala, currently working as an Assistant Professor in K.S.R. College of Arts \& Science has received the B.Sc(CS) from the Bharathiar University, M.Sc(CS) from the Periyar University, M.C.A. from Periyar University, M. Phil from Periyar University, PGDPM \& IR from Alagappa university in 2001, 2003, 2006, 2008 and 2009 respectively. And she is currently pursuing her $\mathrm{Ph} . \mathrm{D}$ in computer science at Bharathiar University. Her area of Doctoral research is Web mining. She secured University First Rank in M.Sc(CS) Programme under Periyar University and received Gold Medal from Tamilnadu State Governor Dr.RamMohanRao in 2004. She has published 5 papers in International Journals, 10 papers in International Conferences/Seminars, 27 papers are presented in National Conferences/Seminars and acts as a reviewer for 8 journals and 2 conferences and her papers are cited at various publications including IEEE Xplore, International Journals, Wikispaces and Conference Proceedings. She has totally 42 publications and participated in 5 National Conferences/Seminars and 3 workshops and acted as a reviewer for 8 International journals and 2 conferences. 